\title{
Raman Spectroscopic Study of Carbon Nanotubes Prepared Using Fe/ZnO-Palm Olein-Chemical Vapour Deposition
}

\author{
Syazwan Afif Mohd Zobir, ${ }^{1,2}$ Suriani Abu Bakar, ${ }^{3}$ Saifollah Abdullah,, 2 \\ Zulkarnain Zainal, ${ }^{4}$ Siti Halimah Sarijo, ${ }^{5}$ and Mohamad Rusop ${ }^{1,6}$ \\ ${ }^{1}$ NANO-SciTech Centre, Institute of Science, Universiti Teknologi MARA (UiTM), Selangor, 40450 Shah Alam, Malaysia \\ ${ }^{2}$ School of Physics and Materials Studies, Faculty of Applied Sciences, Universiti Teknologi MARA (UiTM), Selangor, \\ 40450 Shah Alam, Malaysia \\ ${ }^{3}$ Department of Physics, Faculty of Science and Mathematics, Universiti Pendidikan Sultan Idris, 35900 Tanjung Malim, Malaysia \\ ${ }^{4}$ Faculty of Science, Universiti Putra Malaysia (UPM), Selangor, 43400, Serdang, Malaysia \\ ${ }^{5}$ Department of Chemistry, Faculty of Applied Sciences, Universiti Teknologi MARA (UiTM), Selangor, 40450 Shah Alam, Malaysia \\ ${ }^{6}$ NANO-Electronic Centre, Faculty of Electrical Engineering, Universiti Teknologi MARA (UiTM), Selangor, \\ 40450 Shah Alam, Malaysia
}

Correspondence should be addressed to Syazwan Afif Mohd Zobir, syzawn@yahoo.com

Received 22 September 2011; Revised 29 October 2011; Accepted 3 November 2011

Academic Editor: Anukorn Phuruangrat

Copyright ( 2012 Syazwan Afif Mohd Zobir et al. This is an open access article distributed under the Creative Commons Attribution License, which permits unrestricted use, distribution, and reproduction in any medium, provided the original work is properly cited.

Multiwalled carbon nanotubes (MWCNTs) were synthesized using Fe/ZnO catalyst by a dual-furnace thermal chemical vapor deposition (CVD) method at $800-1000^{\circ} \mathrm{C}$ using nitrogen gas with a constant flow rate of $150 \mathrm{sccm} / \mathrm{min}$ as a gas carrier. Palm olein (PO), ferrocene in the presence of $0.05 \mathrm{M}$ zinc nitrate, and a p-type silicon wafer were used as carbon source, catalyst precursor, and sample target, respectively. D, G, and $\mathrm{G}^{\prime}$ bands were observed at 1336-1364, 1559-1680, and 2667-2682 $\mathrm{cm}^{-1}$, respectively. Carbon nanotubes (CNTs) with the highest degree of crystallinity were obtained at around $8000^{\circ} \mathrm{C}$, and the smallest diameter of about $2 \mathrm{~nm}$ was deposited on the silicon substrate at $1000^{\circ} \mathrm{C}$.

\section{Introduction}

Carbon nanotubes (CNTs) were first reported by Iijima as multiwall nanotubes (MWCNTs) [1] and as single-wall nanotubes (SWCNTs) 2 years later. Since then, CNTs have attracted a lot of attention due to their superiority, particularly with regard to mechanical and electrical properties, and consequent suitability for a wide range of high-end applications in various fields. Generally, there are three main common techniques for synthesizing CNTs, namely, arc discharge, laser ablation, and thermal chemical vapor deposition (CVD).

Catalysts play an important role in synthesizing CNTs, and there are three main common catalysts that are widely used for the preparation of CNTs, namely, nickel (Ni), iron
(Fe), and cobalt (Co) and their combinations [2]. It has been reported that vertically aligned carbon nanotubes (VACNTs) were synthesized using PO as a carbon precursor by thermal CVD [3]. Similarly, MWCNTs were also synthesized using $\mathrm{ZnO}$ cold wall radio-frequency catalytic CVD [4]. The results show that the presence of $\mathrm{ZnO}$ narrows down the size distribution of the MWCNTs.

In this work, a palm-oil-based cooking oil, in particular, palm olein (PO), was used as a carbon precursor. The significant advantages of the precursor are that it is a very cheap, renewable biomaterial, green, and abundantly available. Owing to these factors, it has a huge potential to be used as the carbon source for the synthesis of CNTs, and therefore, the resulting product can be commercialized at a lower cost. 


\section{Experimental Setup}

Zinc nitrate hexahydrate, hexamethylenetetramine, and ferrocene purchased from Systerm, Riedel-de-Haen, and Acros Organics, respectively, were used without further purification. A (100) p-type silicon wafer with a resistivity of 0 $10 \Omega / \mathrm{cm}$ was purchased from Polishing Corp of America.

The substrate was prepared by cutting the silicon wafer into an area of $1 \mathrm{~cm}^{2}$, cleaned with acetone, ethanol and hydrofluoric acid, and finally dried. PO was mixed with different weight percentages of ferrocene and left for a day. The mixture solution was further mixed with $0.05 \mathrm{M}$ zinc nitrate solution for another 30 minutes, so that the ratio of 30 PO $(2 \% \mathrm{Fe})$ to 20 zinc nitrate was obtained. The MWCNTs were prepared using a dual furnace system with Furnace 1 and Furnace 2 placed in parallel. The prepared substrate was placed at the center of Furnace 2, and the mixture solution was placed in Furnace 1, in a quartz tube. Stoppers were inserted at both the ends of the quartz tube. A gas carrier, namely, nitrogen, with a flow rate of $150 \mathrm{sccm} / \mathrm{min}$, was flushed into the tube to create an inert atmosphere. Furnace 2 was first switched on and heated to $750-1000^{\circ} \mathrm{C}$, and then, Furnace 1 was heated to $500^{\circ} \mathrm{C}$. The deposition time was set at $1 \mathrm{~h}$, followed by an annealing process for $30 \mathrm{~min}$. Characterizations were done on the resulting MWCNTs using a field-emission scanning electron microscope (Zeiss, Supra 40VP) and a Raman spectrophotometer with a laser of $514 \mathrm{~nm}$ wavelength (Horiba Jobin Yvon, LabRam HR800). X-ray diffraction (XRD) patterns of the MWCNTs were recorded on a Shimadzu XRD-6000 diffractometer using $\mathrm{CuK}_{\alpha}(\lambda=1.5405 \AA)$ at $40 \mathrm{kV}$ and $30 \mathrm{~mA}$ at the scan rate of $2^{\circ} \mathrm{min}^{-1}$. HRTEM analysis was done using a Philips, Tecnai $2 \mathrm{G}$.

\section{Results and Discussion}

The microstructure of the MWCNTs was studied by Raman spectroscopy. Raman spectra of the MWCNTs (Figure 1(a)) showed three prominent bands at around $1331-1366 \mathrm{~cm}^{-1}$, $1569-1584 \mathrm{~cm}^{-1}$, and $2667-2682 \mathrm{~cm}^{-1}$, corresponding to the $\mathrm{D}, \mathrm{G}$, and $2 \mathrm{D}$ or $\mathrm{G}^{\prime}$ bands, respectively (Table 1 ). The $\mathrm{D}$ band corresponds to the defects that are associated with the vacancies and the presence of other carbonacous impurities that destroy the graphitic symmetry of the G band $[5,6]$. On the other hand, the $\mathrm{G}$ and 2D bands represent the splitting of the $\mathrm{E}_{2 \mathrm{~g}}$ stretching mode for the graphite and overtone of the D band, respectively.

Previous studies have shown that SWCNTs exhibit a radial breathing mode (RBM) with a wavenumber at 100 $200 \mathrm{~cm}^{-1}[7,8]$. The nonexistence of RBM mode in the Raman spectrum (Figure 1(a)) indicates that the presence of SWCNTs can be ruled out, and therefore, the product of the synthesized material is dominated by MWCNTs. The wavenumbers of MWCNTs are summarized in Table 1.

Generally, the ratio of $I_{G} / I_{D}$ can be used to show the presence of structural defects of the noncrystalline carbonaceous products [9]. A plot of $I_{\mathrm{G}} / I_{\mathrm{D}}$ against deposition temperature (Figure $1(\mathrm{~b})$ ) showed that the crystallinity generally decreases as the deposition temperature increases from 800
TABLe 1: Properties of D, G, and 2D bands of MWCNTs synthesized at $750-1000^{\circ} \mathrm{C}$ studied by Raman Spectroscopy.

\begin{tabular}{lccccc}
\hline $\begin{array}{l}\text { Temperature } \\
\left({ }^{\circ} \mathrm{C}\right)\end{array}$ & \multicolumn{5}{c}{ Wavenumber $\left(\mathrm{cm}^{-1}\right)$} \\
\hline 750 & 1364 & 1569 & 2682 & 1.42 & 0.50 \\
800 & 1361 & 1571 & 2685 & 1.79 & 0.37 \\
850 & 1364 & 1576 & 2680 & 1.36 & 0.56 \\
900 & 1350 & 1577 & 2675 & 1.10 & 0.52 \\
950 & 1343 & 1584 & 2671 & 1.01 & 0.57 \\
1000 & 1336 & 1680 & 2667 & 1.32 & 0.61 \\
\hline
\end{tabular}

to $950^{\circ} \mathrm{C}$. However, it was found that the crystallinity was improved as the temperature was increased from 950 to $1000^{\circ} \mathrm{C}$ with the $I_{\mathrm{G}} / I_{\mathrm{D}}$ value of $1.79-1.01$. Furthermore, the red shift of the $G$ band indicated the reduction in graphitization of the resulting material.

The results obtained in this work were compared with MWCNTs prepared from other natural resources such as turpentine and coconut oil. MWCNTs prepared using both turpentine and coconut oil as the carbon sources were found to have a lower $I_{\mathrm{G}} / I_{\mathrm{D}}$ value when compared with that of PO. This reveals that the microstructural quality of MWCNTs synthesized using $\mathrm{PO}$ is much better than that of turpentine and coconut oil under our experimental conditions. From the microstructure analysis, it can be concluded that the PO has resulted in MWCNTs with better crystallinity and has the potential to be used as a good carbon precursor. This is towards the use of renewable bioresources as the carbon source for CNTs production.

The overtone of the $\mathrm{D}$ band, usually labeled as the $2 \mathrm{D}$ or $\mathrm{G}^{\prime}$ band, can be associated with the degree of crystallinity of the CNTs. The ratio of $I_{2 \mathrm{D}} / I_{\mathrm{G}}$, given in Table 1 and plotted in Figure 1(c), shows that the wavenumbers of the $G$ band are red-shifted from 1571 to $1686 \mathrm{~cm}^{-1}$ as the deposition temperature increased from 750 to $1000^{\circ} \mathrm{C}$, in parallel with a finding from previous works that the degree of graphitization decreased as the wavenumbers of the G band increased [10]. At the same time, it can be noted that the D and G bands are blue-shifted. This shows that the deposition temperature also affects the graphitization degree of the resulting MWCNTs.

A more uniform size of MWCNTs was observed under our experimental method, when compared with the dense bundles of mixed MWCNTs and SWCNTs obtained by previous study [3], and the introduction of $\mathrm{ZnO}$ as a supported catalyst used in this work was found to reduce the size distribution of MWCNTs. In addition, the method of preparation is relatively simple, that is, only mixing of the $\mathrm{PO}$ with $0.05 \mathrm{M}$ zinc nitrate and $2 \%$ ferrocene $(\mathrm{w} / \mathrm{w})$, followed by pyrolysis.

Figure 2 shows the morphology of MWCNTs deposited on a silicon substrate at different temperatures. Linear and helical structures [11] were observed at a lower deposition temperature of $850^{\circ} \mathrm{C}$ (Figure 2(a)). When the temperature was increased to $950^{\circ} \mathrm{C}$, a necklace-like MWCNTs $[12,13]$ became dominant, with a smaller diameter of around 3-4 nm (Figure 2(b)). At $1000^{\circ} \mathrm{C}$, a more uniform distribution of 


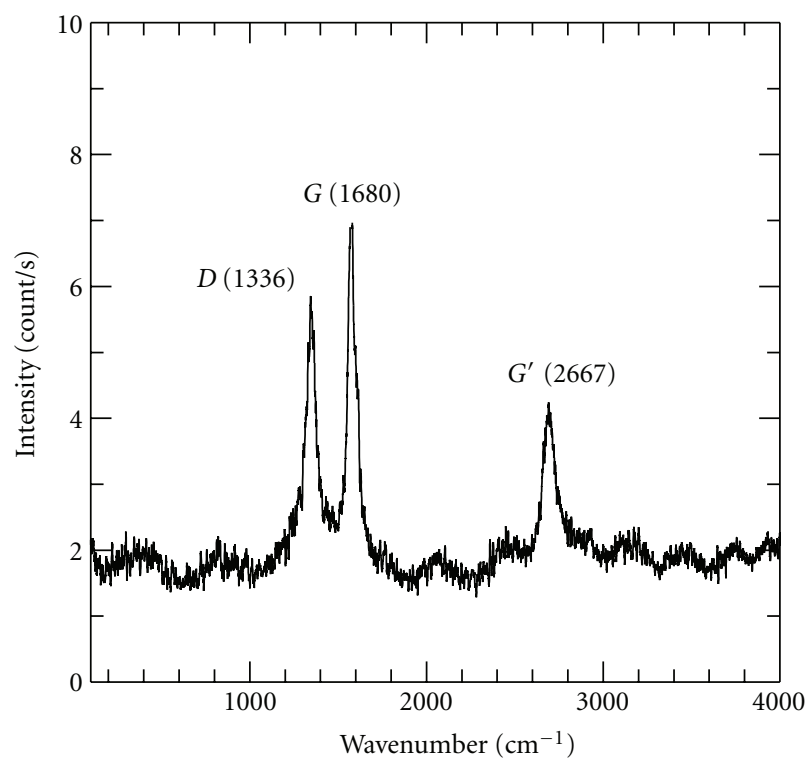

(a)

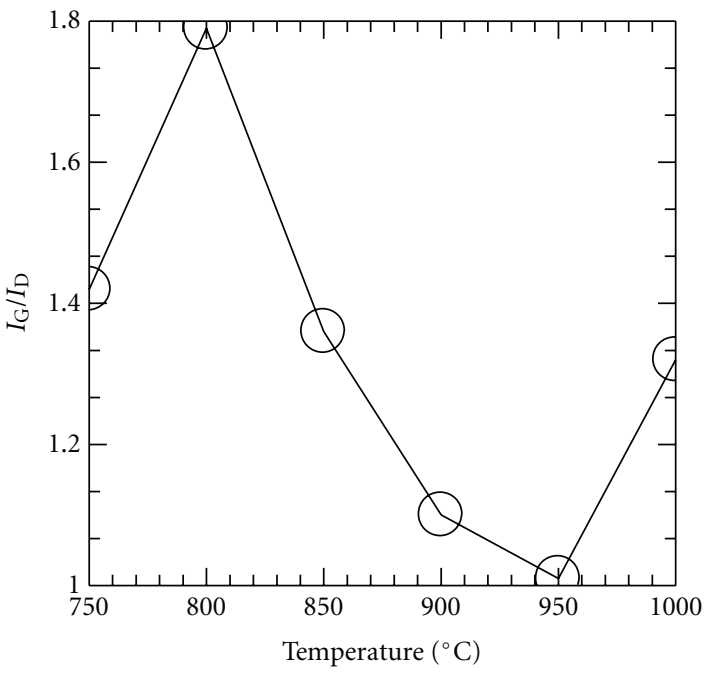

(b)

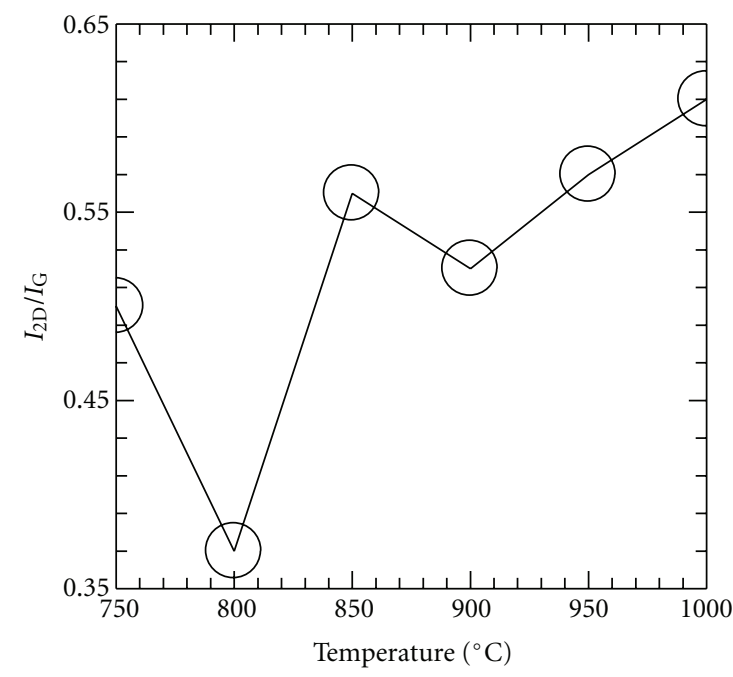

(c)

Figure 1: (a) Typical Raman spectrum of MWCNTs showing the absence of RBM at around 100-200 $\mathrm{cm}^{-1}$; (b) plot of deposition temperature of the MWCNTs against $I_{\mathrm{G}} / I_{\mathrm{D}}$; (c) plot of deposition temperature of the MWCNTs against $I_{2 \mathrm{D}} / I_{\mathrm{D}}$.

MWCNTs was observed with a diameter of around $80 \mathrm{~nm}$, but the presence of small diameter of $2 \mathrm{~nm}$ could still be observed (Figure 2(c) on the right).

Recently, Paul and Samdarshi [14] reported that the diameters of a random-orientation CNTs of around 80$90 \mathrm{~nm}$ were obtained when coconut oil was used as the carbon precursor. Similarly, turpentine oil was also used by Ghosh et al. to synthesize VACNTs with a diameter of 7-30 nm [15]. In this work, the surface morphology study showed that the smallest diameter obtained was around $2 \mathrm{~nm}$ when $\mathrm{PO}$ was used as the carbon precursor, and that it possessed a higher graphitic-to-defect ratio, when compared with other methods previously reported.
Figure 3 shows the high-resolution transmission electron microscope (HRTEM) images of MWCNTs at lower and higher magnifications. Carbon of nanotubes type can be clearly observed (Figure 3(a)) and a bamboo-like multiwalled structure is clearly visible in Figure $3(\mathrm{~b})$ with a thickness of around $20-25 \mathrm{~nm}$. This is in agreement with the absence of RBM wavenumbers at $100-200 \mathrm{~cm}^{-1}$ in the Raman spectrum, as shown in Figure 1(a), indicating that the product of the synthesis is exclusively MWCNTs without any presence of SWCNTs.

Energy dispersive X-ray spectroscopy (EDX) was also used to identify the elements existing in the samples. Several elements were detected, such as carbon, oxygen, iron, zinc, 

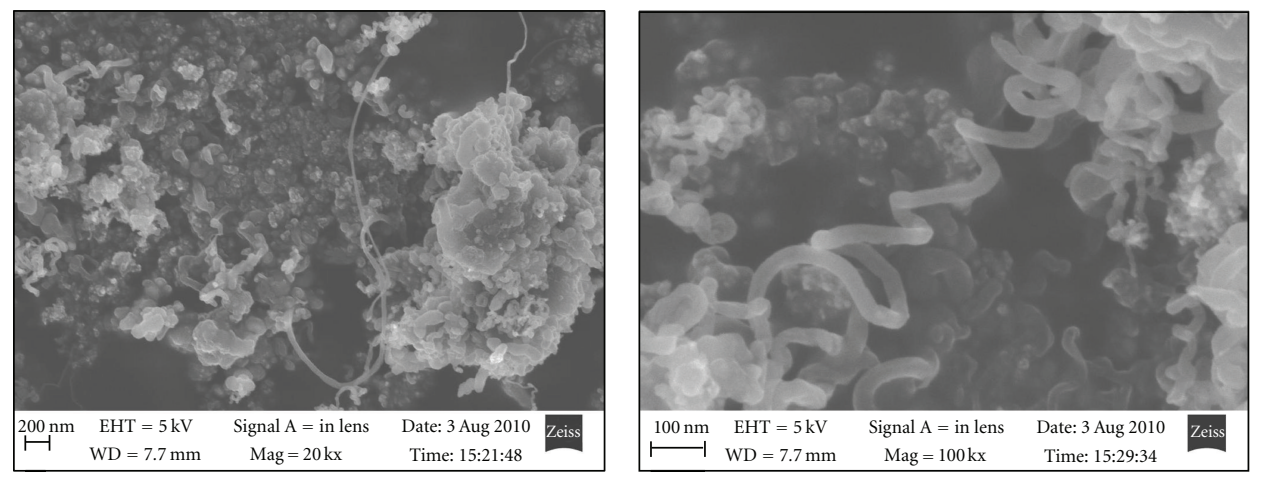

(a)
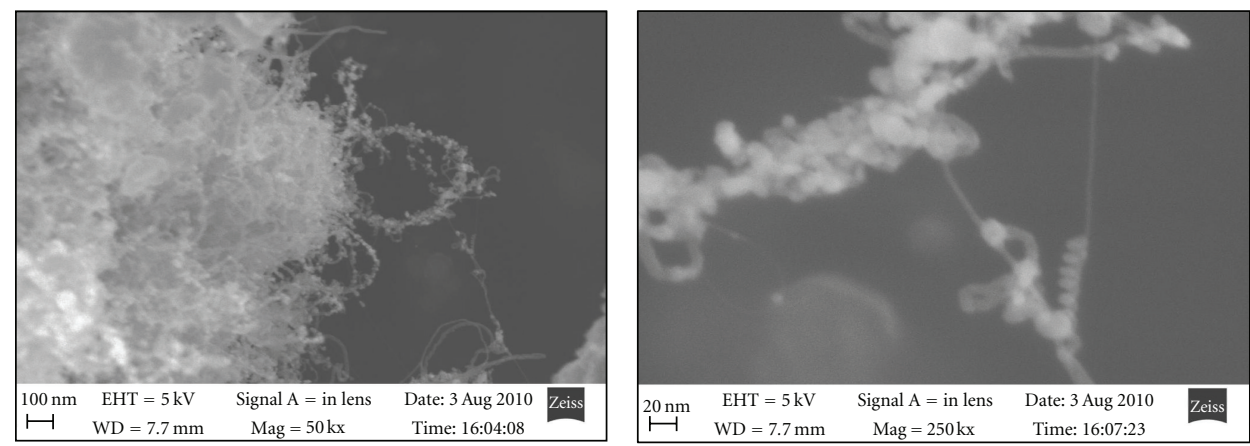

(b)
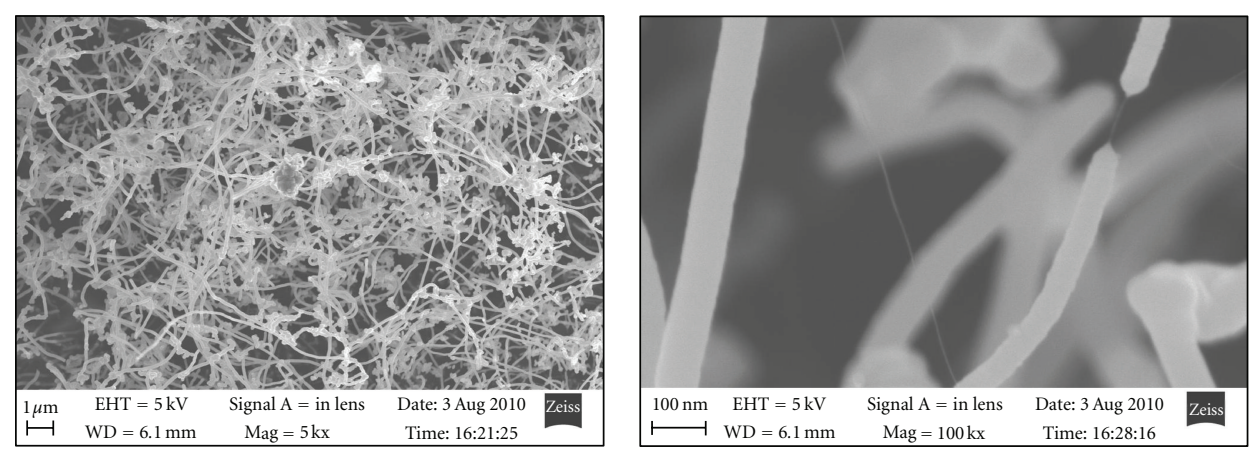

(c)

Figure 2: Surface morphology of MWCNTs synthesized using PO as the carbon source at (a) 850, (b) 950 , and (c) $1000^{\circ} \mathrm{C}$. Higher magnification is given on the right.

and silicon, as shown in Figure 4. Carbon is the main element of the CNTs, while zinc and iron are present due to the catalysts. On the other hand, the silicon detected is due to the substrate used to deposit the MWCNTs.

X-ray diffraction (XRD) technique was used to determine the phases that exist on the resulting synthesized products (Figure 5). As shown in the figure, there are three phases coexisted namely zinc oxide [16], graphitic carbon [17] and iron oxide [18]. The presence of crystalline graphitic carbon instead of the amorphous phase clearly indicates that no coformation of amorphous carbon phase exists in the resulting product, and the carbon product is generally of MWCNTs type.

\section{Conclusions}

This study shows that MWCNTs can be synthesized by CVD method using PO as the carbon source. The smallest diameter of MWCNTs of about $2 \mathrm{~nm}$ was deposited on the silicon substrate at $1000^{\circ} \mathrm{C}$. The highest crystallinity of carbon, $I_{\mathrm{G}} / I_{\mathrm{D}}$, was formed at $800^{\circ} \mathrm{C}$. As the deposition temperature increased, the degree of crystallinity of the CNTs decreased due to more defects being introduced, possibly as a result of the coformation of nongraphitic carbons. The product of the synthesis exhibited a non-RBM of Raman Spectra and the HRTEM showed that the thickness of the walls was about $20-25 \mathrm{~nm}$, indicating MWCNTs were formed. EDX, together with XRD analyses, proved that $\mathrm{ZnO}$ 


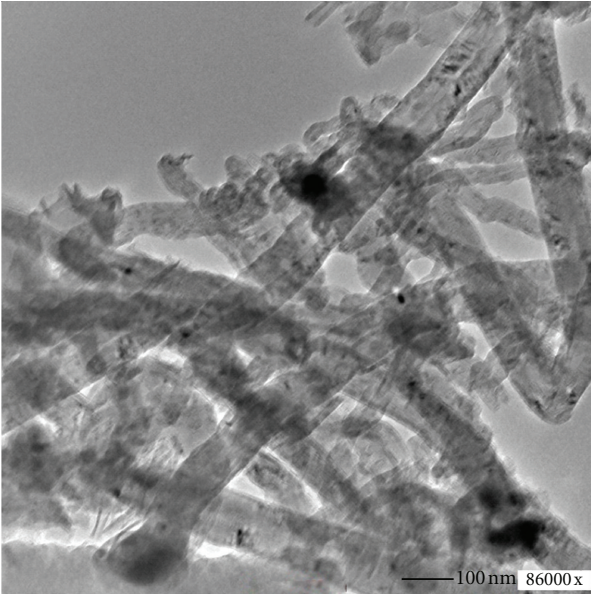

(a)

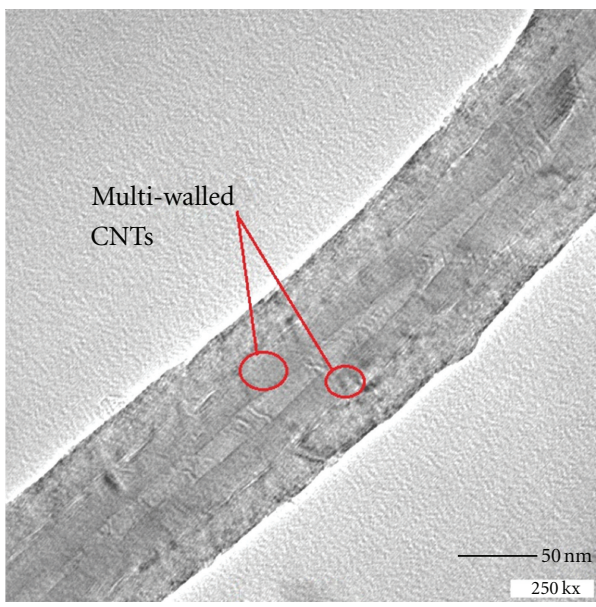

(b)

Figure 3: HRTEM images of the MWCNT synthesis at $1000^{\circ} \mathrm{C}$; at (a) lower magnification and (b) higher magnification.

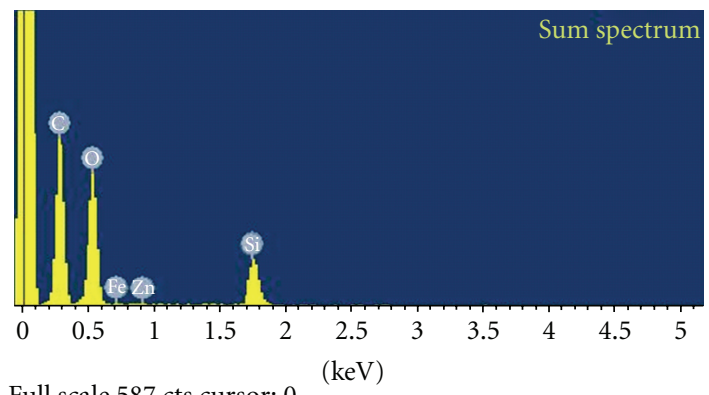

Figure 4: A typical EDX of CNTs.

phase was also formed during the formation of MWCNTs from PO.

\section{Acknowledgments}

SAMZ thanks UiTM for SKS, and the Faculty of Applied Sciences and Institute of Science (IOS) for the assistantship

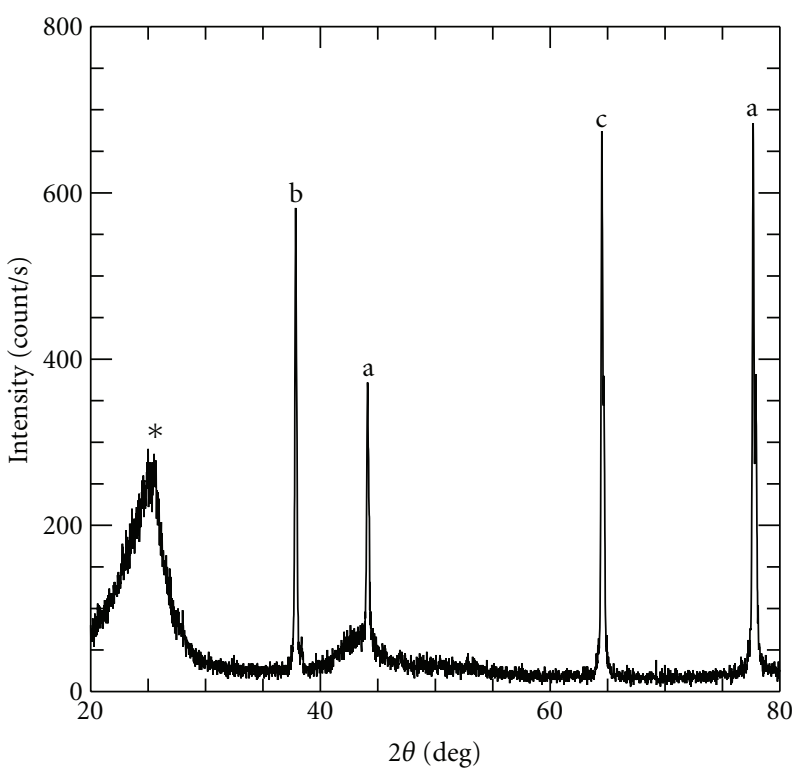

FIGURE 5: A typical XRD pattern of MWCNTs showing the presence of graphitic carbon (a) and zinc oxide (b) and iron oxide phases (c), ghost peak $(*)$.

and sponsorships. The authors also thank Mr. Abdul Karim Ishak from Microscopy Imaging Centre, Faculty of Pharmacy, UiTM Puncak Alam, for the HRTEM images.

\section{References}

[1] S. Iijima, "Helical microtubules of graphitic carbon," Nature, vol. 354, no. 6348, pp. 56-58, 1991.

[2] A. A. Azira, N. F. A. Zainal, S. F. Nik et al., "Properties of carbon nanotubes synthesised using fluidized floating catalyst method from camphor oil," Malaysian Journal of Science, vol. 28 , pp. 123-128, 2009.

[3] A. B. Suriani, A. A. Azira, S. F. Nik, R. Md Nor, and M. Rusop, "Synthesis of vertically aligned carbon nanotubes using natural palm oil as carbon precursor," Materials Letters, vol. 63, no. 30, pp. 2704-2706, 2009.

[4] D. Lupu, A. R. Biris, F. Watanabe et al., "Synthesis of narrow diameter distribution carbon nanotubes on $\mathrm{ZnO}$ supported catalysts," Chemical Physics Letters, vol. 473, no. 4-6, pp. 299304, 2009.

[5] S. Lefrant, M. Baibarac, I. Baltog, J. Y. Mevellec, C. Godon, and O. Chauvet, "Functionalization of single-walled carbon nanotubes with conducting polymers evidenced by Raman and FTIR spectroscopy," Diamond and Related Materials, vol. 14, no. 3-7, pp. 867-872, 2005.

[6] S. Kamikura, T. Uchida, K. Naka, T. Asaji, H. Uchiyama, and Y. Yoshida, "Single-walled carbon nanotube growth using cobalt nanoparticles prepared by vacuum deposition on a surfaceactive liquid," Diamond and Related Materials, vol. 20, no. 7, pp. 863-865, 2011.

[7] K. Kobayashi, R. Kitaura, Y. Kumai, Y. Goto, S. Inagaki, and H. Shinohara, "Synthesis of single-wall carbon nanotubes grown from size-controlled $\mathrm{Rh} / \mathrm{Pd}$ nanoparticles by catalystsupported chemical vapor deposition," Chemical Physics Letters, vol. 458, no. 4-6, pp. 346-350, 2008. 
[8] Y. Wang, Z. Zhang, H. Liu et al., "The effect of catalyst concentration on the synthesis of single-wall carbon nanotubes," Spectrochimica Acta, vol. 58, no. 10, pp. 2089-2095, 2002.

[9] G. Zou, D. Zhang, C. Dong et al., "Carbon nanofibers: synthesis, characterization, and electrochemical properties," Carbon, vol. 44, no. 5, pp. 828-832, 2006.

[10] J. Liu, Y. Zhang, M. I. Ionescu, R. Li, and X. Sun, "Nitrogendoped carbon nanotubes with tunable structure and high yield produced by ultrasonic spray pyrolysis," Applied Surface Science, vol. 257, no. 17, pp. 7837-7844, 2011.

[11] T. Luo, J. Liu, L. Chen, S. Zeng, and Y. Qian, "Synthesis of helically coiled carbon nanotubes by reducing ethyl ether with metallic zinc," Carbon, vol. 43, no. 4, pp. 755-759, 2005.

[12] D. Zhang, C. Pan, J. Zhang, and L. Shi, "Solvothermal synthesis of necklace-like carbon nanotube/ceria composites," Materials Letters, vol. 62, no. 23, pp. 3821-3823, 2008.

[13] A. Aguilar-Elguézabal, D. Lardizábal, W. Antúnez-Flores, and F. Paraguay-Delgado, "A novel necklace like structure assembled with MCM-41 and carbon nanotubes," Journal of Alloys and Compounds, vol. 466, no. 1-2, pp. 521-524, 2008.

[14] S. Paul and S. Samdarshi, "A green precursor for carbon nanotube synthesis," New Carbon Materials, vol. 26, no. 2, pp. 85-88, 2011.

[15] P. Ghosh, T. Soga, K. Ghosh, R. A. Afre, T. Jimbo, and Y. Ando, "Vertically aligned N-doped carbon nanotubes by spray pyrolysis of turpentine oil and pyridine derivative with dissolved ferrocene," Journal of Non-Crystalline Solids, vol. 354, no. 34, pp. 4101-4106, 2008.

[16] S. Kumar, Y. J. Kim, B. H. Koo et al., "Room temperature ferromagnetism in chemically synthesized $\mathrm{ZnO}$ rods," Materials Letters, vol. 63, no. 2, pp. 194-196, 2009.

[17] T. Takamura, K. Endo, L. Fu, Y. Wu, K. J. Lee, and T. Matsumoto, "Identification of nano-sized holes by TEM in the graphene layer of graphite and the high rate discharge capability of Li-ion battery anodes," Electrochimica Acta, vol. 53, no. 3, pp. 1055-1061, 2007.

[18] J. Zieliński, I. Zglinicka, L. Znak, and Z. Kaszkur, "Reduction of $\mathrm{Fe}_{2} \mathrm{O}_{3}$ with hydrogen," Applied Catalysis A, vol. 381, no. 1-2, pp. 191-196, 2010. 

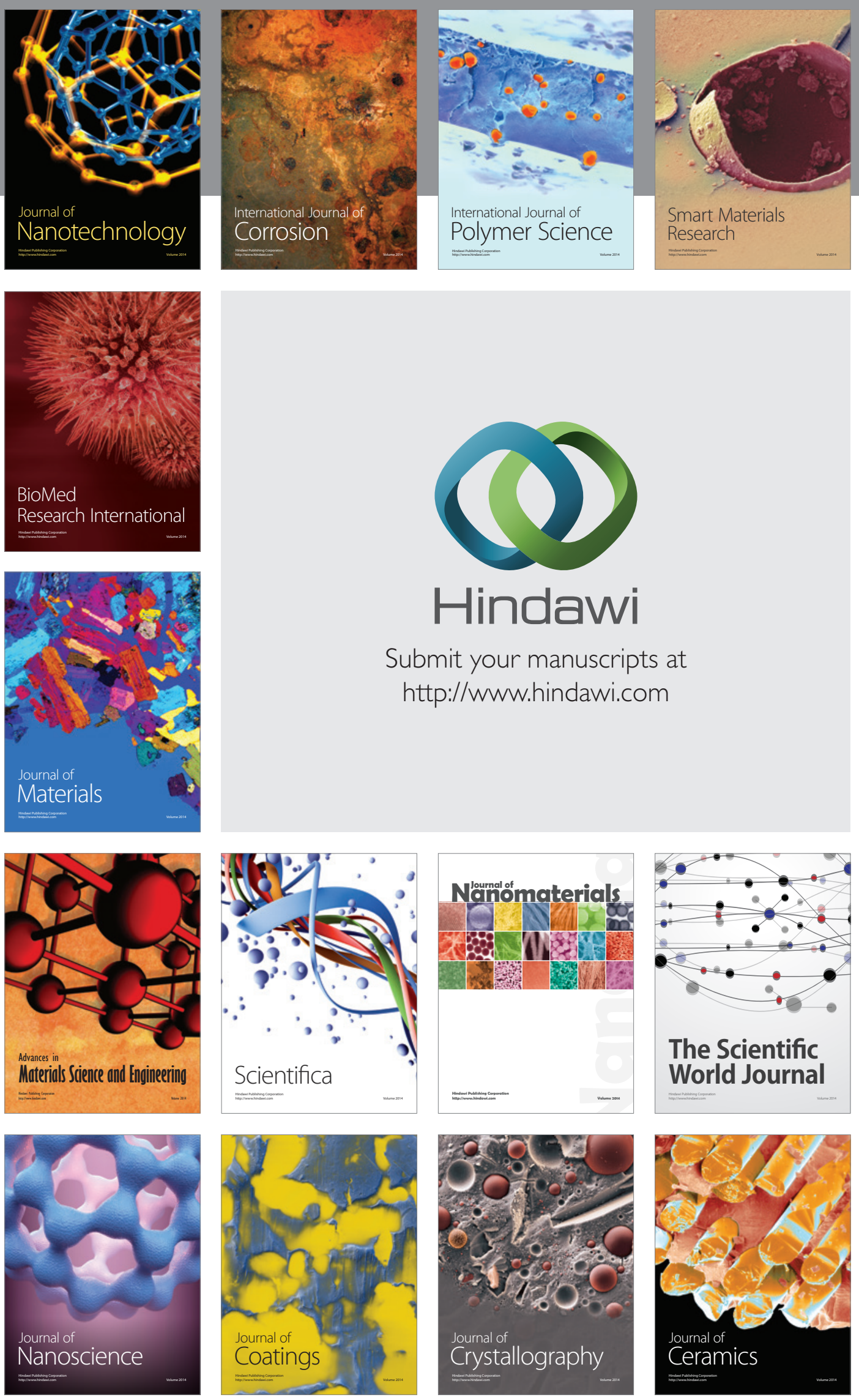

The Scientific World Journal

Submit your manuscripts at

http://www.hindawi.com

\section{World Journal}

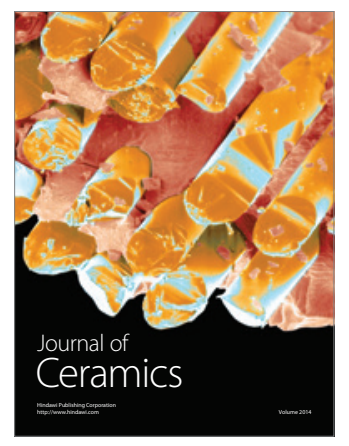

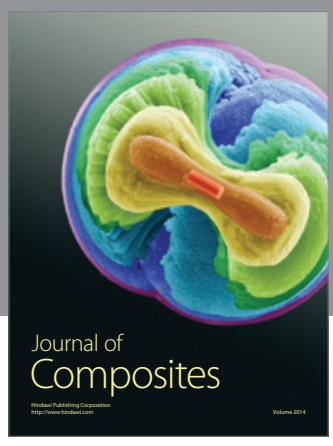
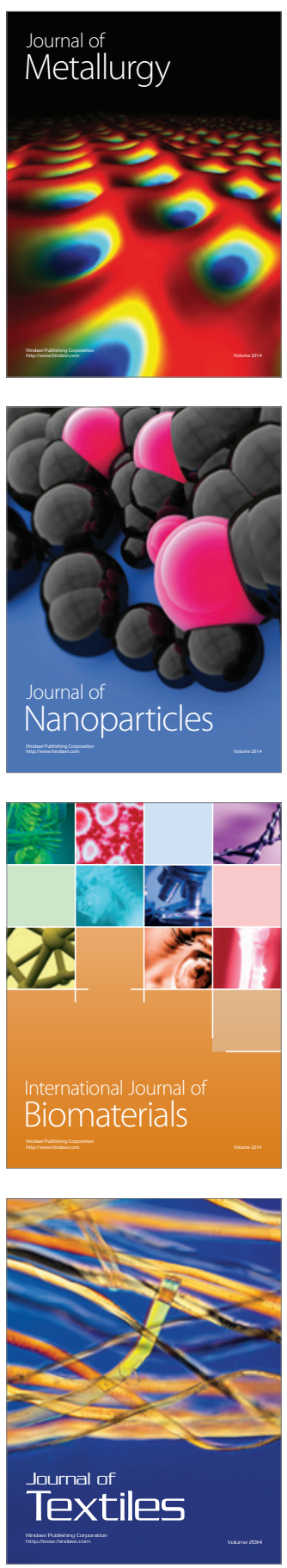